\title{
LAS SOCIEDADES ECONÓMICAS DE AMIGOS DEL PAÍS: PROYECTO Y REALIDAD EN LA ESPAÑA DE LA ILUSTRACIÓN ${ }^{1}$
}

\author{
Inmaculada Arias de SaAvedra Alías \\ Universidad de Granada
}

\begin{abstract}
Resumen. Las Sociedades Económicas de Amigos del País son una de las más interesantes y mejor conocidas realizaciones de la Ilustración española. Este artículo es un estudio de conjunto de éstas, prestando atención a sus orígenes, etapas de creación, composición social, organización interna y realizaciones, tanto en el campo de la educación, como en el de la economía. En resumen, se trata de un balance historiográfico del tema, que puede ser de utilidad para los estudiosos del siglo XVIII.
\end{abstract}

Palabras clave: Sociedades Económicas. Ilustración. Educación. Economía. Siglo XVIII.

\begin{abstract}
The Economic Societies are one of the most interesting and best known achievements of the Spanish Enlightenment. This article is a study of the Economic Societies as a whole, focusing in particular on their origins, the steps to their creation, social composition, internal organization and especially on their achievements, in the fields both of the education and of the economy. It sums up the state of historical enquiry on the subject to date, and will be of value to all students of the eighteenth century.
\end{abstract}

Keywords: Economic Societies. Enlightenment. Education. Economy. Eighteenth Century.

Las Sociedades Económicas de Amigos del País son una de las creaciones más interesantes y mejor conocidas del reformismo ilustrado español. Hace más de veinte

\footnotetext{
Recibido: 8 marzo 2012 Aceptado: 25 abril 2012

1 Estudio realizado en el marco del Proyecto HAR2011-26435-CO3-03 del Ministerio de Cien-
} cia e Innovación. 
años M. García Ruipérez publicaba una recopilación bibliográfica ${ }^{2}$ con más de doscientos trabajos sobre esta temática y poco después M.Velázquez ofrecía una detallada panorámica historiográfica sobre estas instituciones ${ }^{3}$. Aunque parecía un tema suficientemente conocido, con posterioridad nuevos títulos han ido apareciendo.

Las Sociedades Económicas son unos institutos de larga vida. Creadas en el último tercio del siglo XVIII, muchas sobrevivieron en el siglo siguiente y las más importantes continúan en la actualidad. Pero no han conservado la misma naturaleza y significación. Como suele ocurrir con instituciones de larga pervivencia, han ido cambiando, adaptándose a las condiciones económicas, sociales y políticas en las que se han inscrito. La etapa, a mi juicio, más interesante es la comprendida entre su nacimiento y 1808. Durante estos años fueron un "conducto de ilustración" y encarnaron el espíritu reformista que animó a los sectores más dinámicos de la sociedad española ${ }^{4}$.

\section{Precedentes de las Económicas: La Sociedad Bascongada de Amigos del País}

Casi todos los estudiosos de las Sociedades Económicas se han planteado cómo se produce su génesis y han buscado los antecedentes que las inspiraron. En general se las considera un exponente más del movimiento europeo de creación de tertulias, academias y sociedades para difundir los conocimientos e impulsar las reformas. En concreto, su antecedente estaría en las academias de carácter más pragmático y utilitario, preocupadas por los problemas agrarios y económicos. La influencia se concreta en las Sociedades de Dublín, Bretaña y Berna, preocupadas por la agricultura, in-

2 GARCÍA RUIPÉREZ, M.: Nuevas aportaciones al estudio de las Sociedades Económicas de Amigos del País, Madrid, CSIC, 1988.

3 VELÁZQUEZ MARTÍNEZ, M.: La Sociedad Económica de Amigos del País del Reino de Murcia: La Institución, los Hombres y el Dinero (1777-1820), Murcia, Consejería de Cultura, 1989, pp. 19-35.

4 Síntesis sobre ellas en SARRAILH, J.: La España ilustrada de la segunda mitad del siglo XVIII, México, FCE,1957, pp. 230-290; HERR, R.: España y la revolución del siglo XVIII, Madrid, Aguilar, 1964, pp. 129-136; CARANDE Y THOVAR, R.: "El despotismo ilustrado de los Amigos del País", en Siete estudios de Historia de España, Barcelona, Ariel, 1976, pp. 143-161; ANES, G.: "Coyuntura económica e Ilustración. Las Sociedades Económicas de Amigos del País”, en Economía e Ilustración en la España del siglo XVIII, Barcelona, Ariel, 1981, pp. 13-41; ENCISO RECIO, L.M.: "Las Sociedades Económicas de Amigos del País", en La época de las Ilustración. El Estado y la cultura (1759-1808), t. XXXI de la Historia de España, de Menéndez Pidal-Jover, Madrid, Espasa Calpe, 1987, pp. 13-31 y del mismo autor: Las Sociedades Económicas en el siglo de las luces, Madrid, Real Academia de la Historia, 2010, donde se reeditan diversos trabajos ya publicados. Las fuentes para su estudio en: DEMERSON, P. y J. y AGUILAR PINAL, F.: Las Sociedades Económicas de Amigos del País en el siglo XVIII. Guia del investigador, San Sebastián, Izarra, 1974. 
dustria y comercio, así como en la Academia de Agricultura de Florencia, más centrada en los temas específicamente agrarios ${ }^{5}$, instituciones coincidentes con el avance del pensamiento fisiocrático. En nuestro país se crearon también instituciones de este tipo como la Reales Academias de Agricultura de Lérida y del Reino de Galicia ${ }^{6}$. También se suele considerar un importante antecedente la publicación del Proyecto económico, de Bernardo Ward, escrito en 1762 pero impreso en 1779, donde se propone la creación de una Junta de mejoras de carácter nacional, pero con delegaciones provinciales, con objetivos bastante similares a los de las Económicas: estudiar las causas del estancamiento económico de España y proponer remedios, atrayendo a los elementos más activos de la sociedad, en particular a la nobleza y a los hacendados. Esta obra ejerció gran influencia en Campomanes y a través de él en las Sociedades de Amigos del País?

Pero, sin duda, el precedente más importante de la creación de Sociedades Económicas auspiciada por el gobierno fue el nacimiento, espontáneo y debido a la iniciativa privada, de la Sociedad Bascongada de Amigos del País. Su germen fueron las tertulias de ilustrados de las provincias vascas, más concretamente la tertulia de Azcoitia, auspiciada por el conde de Peñaflorida. A partir de 1748 las tertulias, hasta entonces informales, empezaron a reglamentarse. La de Azccoitia se transformó en junta académica, adoptando un plan para la distribución regular de las materias en las reuniones y, en la línea de los novatores, se alineó dentro del nuevo pensamiento newtoniano, promoviendo las lecturas y publicaciones científicas. En 1763 Peñaflorida redactó un Plan de una Sociedad económica o academia de agricultura, Ciencias, Artes útiles y Comercio, que inicialmente agrupaba a los ilustrados guipuzcoanos, pero que pronto se abrió a los de las tres provincias vascas. En diciembre de 1764 un grupo de 19 políticos forales nobles, fundó en Azcoitia la Sociedad Bascongada, redactó sus primeros estatutos y adoptó el nombre de "Amigos del País", así como el lema: "Irurac bat", tres en una, en alusión a las tres secciones de cada una de las provincias vascas. En 1765 el Secretario de Estado Grimaldi comunicó la aprobación real ${ }^{8}$.

5 AStigarRagA, J.: “Campomanes y las Sociedades Económicas de Amigos del País", en MATEOS DORADO, D.: Campomanes doscientos años después, Oviedo, Universidad de Oviedo-Instituto Feijoo, 2003, pp. 617-667.

6 LLUCH, E.: El pensament econòmic a Catalunya (1760-1840), Barcelona, Edicions 62, 1973, pp. 160-166; DOPICO, F.: A Ilustración e a sociedade galega. A visión de Galicia dos economistas ilustrados, Vigo, Editorial Galaxia, 1978, pp. 43-51; ABAD FLORES, O.: Sobre la Academia de Agricultura de La Coruña, La Coruña, Instituto José Cornide de Estudios Coruñeses, 1984 y DEMERSON, P. y J.: "Una pionera: la Academia de Agricultura de Galicia, decana de las Sociedades Económicas de España", en Homenaje a Pedro Sáinz Rodríguez. III. Estudios históricos, Madrid, FUE, 1986, pp. 203-217.

7 WARD, B.: Proyecto económico. Edición y estudio preliminar por Juan Luis Castellano, Madrid, Instituto de Estudios Fiscales, 1982.

8 ASTIGARRAGA, J.: Los ilustrados vascos. Ideas, instituciones y reformas económicas en España, Barcelona, Crítica, 2003, pp. 23-48. 
Jesús Astigarraga ha señalado la extracción nobiliaria de los fundadores de la Sociedad Bascongada, así como su alto nivel cultural y la amplitud de sus relaciones exteriores. Estos ilustrados vascos tenían rentas agrarias, pero también industriales (ferrerías, construcción naval) y comerciales. Por eso la Bascongada presenta un modelo menos basado en el desarrollo de la agricultura que el resto de las Económicas. $\mathrm{Su}$ preocupación por la industria y el comercio fue mayor que en otros institutos. Los fundadores, en su mayoría titulares de mayorazgos, tenían acceso a las Juntas Generales de Guipúzcoa, lo que facilitó la fundación de la Sociedad. Pertenecían a familias vinculadas a la administración y al ejército, pero por lo general sus socios permanecían en la casa familiar, gobernándola y ocupando cargos a escala local y provincial. Pronto la base social de la Bascongada se abriría al mundo del comercio, especialmente en San Sebastían y Bilbao (Consulado y Compañía Guipuzcoana), profesionales (médicos y profesores de Vergara), personal de la administración, funcionarios, etc. Su composición social iría cambiando, a medida que alcanzaba un mayor número de socios, muy elevado por cierto, llegó a superar los 1.800 socios y a fines de los ochenta se estabilizó en torno a 1200-1300, algo extraordinario. Este número se debió a su expansión por toda España, especialmente por la Corte y ciudades como Sevilla, Cádiz y Pamplona, y más tarde incluso por el continente americano, sobre todo por las ciudades de México, Buenos Aires y Lima. Con tan elevado número de socios conseguiría financiarse con las cuotas de sus miembros ${ }^{9}$.

Según sus Estatutos, la Bascongada nacía con la intención de "fomentar la agricultura, la industria, el comercio, las artes y las ciencias", por eso sus socios se estructuraron en cuatro comisiones: "Agricultura, Ciencias y artes útiles, Industria y comercio y finalmente Historia, política y buenas letras". Con gran capacidad de integración, planteó una estrategia reformadora coincidente con los intereses de los consulados de comercio de Bilbao y San Sebastián.

No podemos extendernos aquí en glosar con detalle las realizaciones de la Bascongada. En el terreno económico, sobre alguno de cuyos aspectos se volverá más adelante, destacan sus esfuerzos por mejorar la productividad agraria, a través de la difusión de las corrientes agronómicas francesas y británicas; su interés por mejorar las industrias de hierro y siderúrgica, creando cátedras de química, metalurgia o mineralogía y emprendiendo experiencias para mejorar la producción; o la defensa de la honorabilidad del comercio y la adopción de medidas liberalizadoras. Desde sus primeros años se ocupó de una forma muy especial por los temas educativos. Envió becarios al extranjero, para formarse en mineralogía y metalurgia, e importó profesores como Proust, Chavaneaux o los hermanos Elhuyard. Destaca, así mismo, la creación

$9 \quad$ Ibidem, pp. 64-65. 
de una Escuela de Náutica en San Sebastián, la formación de una importante biblioteca de temas científicos y literarios y sobre todo la creación del Seminario de Nobles de Vergara.

Calificado por Menéndez Pelayo como la primera escuela laica de España, sus enseñanzas representan un gran avance respecto a colegios similares de la época. $\mathrm{Su}$ plan de estudios era muy avanzado. Además de las obligadas enseñanzas de primeras letras, humanidades y religión, se impartían en él un amplio elenco de materias científicas: matemáticas, geometría, física, química, agricultura, mineralogía, metalurgia, al lado de otras como comercio, economía política y lenguas modernas. Llama la atención el interés por las enseñanzas vinculadas a la riqueza de la zona (minería, agricultura, actividad comercial), así como por los idiomas, que permitan acceder a los avances europeos ${ }^{10}$.

Por las aulas de este centro, aprobado en 1776, pasaron más de 500 alumnos hasta 1804. El factor familiar era muy fuerte entre ellos, abundan los hermanos y primos. Por lo general, las familias de los seminaristas estaban vinculadas al servicio de la corona, con cargos en la administración y en el ejército. En los primeros años procedían de las provincias vascas. Pronto su número se multiplicó y vinieron de otros lugares como la Corte, Andalucía y América. Sólo una cuarta parte del total eran vascos y casi el 20 por ciento llegaba de territorios americanos, especialmente de La Habana. La salida profesional de los seminaristas fue mayoritariamente el ejército, continuando su formación como cadetes en otros centros, como la Academia militar de Segovia -el estudiar en Vergara les otorgaba el necesario reconocimiento nobiliar-, y en menor medida la administración. La formación científica que adquirían, de claro corte técnico, era muy rica en conocimientos que podían aplicarse en el ejército. La élite gobernante que enviaba a sus hijos a educarse en el seminario, conseguía darles carrera al servicio del rey ${ }^{11}$.

\section{El impulso de Campomanes y la fundación de las Sociedades Económicas}

Tras la constitución de la Bascongada en 1765, sólo surgieron en nuestro país dos pioneras Sociedades Económicas a imitación de la organización vasca, sin impulso oficial alguno: la Sociedad Tudelana de los Deseosos del bien público, promovida

10 SILVÁN, L.: Los estudios cientificos en Vergara a fines del siglo XVIII, San Sebastián, Biblioteca Vascongada de los Amigos del País, 1953 y RECARTE BARRIOLA, M.T.: Ilustración vasca y renovación educativa. La Real Sociedad Bascongada de Amigos del País, Salamanca, Universidad PontificiaReal Sociedad Bascongada de Amigos del País, 1990.

11 CHAPARRO SÁINZ, Á.: Educarse para servir al Rey: El Real Seminario Patriótico de Vergara (1776-1804), Zarautz, Universidad del País Vasco, 2011. 
en 1773 por el marqués de San Adrián, en estrecha conexión con el grupo de Peñaflorida, y la Sociedad de Verdaderos Patricios de Baeza y Reino de Jaén, nacida a principios de 1774 a partir de una tertulia que agrupaba a la nobleza y el clero locales ${ }^{12}$. El resto de las Sociedades Económicas fueron promovidas por el poder central. El punto de partida debe fijarse en noviembre de 1774, con la publicación del Discurso sobre el fomento de la industria popular de Campomanes. En esta obra se diseñaba un plan para crear Económicas y se trazaban sus líneas maestras ${ }^{13}$.

Una tirada de 30.000 ejemplares del discurso, fabulosa para la época, junto con una circular exhortando a la creación de las Sociedades Económicas, se difundieron por corregimientos, municipios, chancillerías, audiencias, obispados, etc.; se pretendía que las autoridades civiles y eclesiásticas promovieran fundaciones por toda la monarquía ${ }^{14}$. Las sugerencias de Campomanes fueron bien acogidas. Pronto empezaron a llegar al Consejo de Castilla solicitudes de ciudades y villas de todo el reino para fundar Económicas.

Gonzalo Anes recopiló hace años el proceso de solicitudes de creación y de aprobación de estos institutos. Entre 1775 y 1808 se promovieron $97^{15}$. El ritmo fundacional no fue uniforme. Entre 1775 y 1780 aparecieron 40, entre otros los más importantes y activos, a partir de 1780 abundaron los surgidos en poblaciones menores. La etapa hasta mediados de los 80 coincide con la mayor actividad de las Económicas, que pronto empezaron a dar muestras de cierto agotamiento, hasta el punto que en 1786 el Consejo promovería una encuesta para explicar las causas de su decadencia $^{16}$. La década de los noventa no fue propicia para nuevas creaciones, debido a la coyuntura anti-ilustrada frente a la revolución francesa. En los años iniciales de la centuria siguiente las nuevas fundaciones serían muy escasas.

La distribución geográfica de las Económicas no fue uniforme. Mientras que en Asturias, Aragón, Cantabria, Galicia, La Rioja, Mallorca, Murcia y Valencia predomina una sociedad única o casi única de alcance regional ${ }^{17}$, en otras zonas se multiplicaron las fundaciones. En Andalucía surgieron 32, prácticamente un tercio de las Económicas de todo el país. Además de en las cuatro capitales (Sevilla, Granada,

12 ARIAS DE SAAVEDRA ALÍAS, I.: Las Sociedades Económicas de Amigos del País del Reino de Jaén, Jaén, Diputación Provincial-Universidad de Granada, 1987, pp. 107-188.

13 Discurso sobre el fomento de la industria popular, Madrid, Imprenta de D. Antonio de Sancha, 1774. Se ocupa de las Económicas en los capítulos IX, XIX y XX.

14 La circular, de fecha 18 de noviembre de 1774, en Archivo Histórico Nacional (AHN), Reales Cédulas, núm. 393.

15 ANES, G.: “Coyuntura...”, art. cit., pp. 26-30.

16 DEMERSON, J. y P.: "La decadencia de las Reales Sociedades de Amigos del País", BOCES XVIII, 4 y 5 (1977), pp. 87-190.

17 FAYA DÍAZ, M.A.: "La Sociedad Económica de Asturias: un balance", en La época de Carlos IV (1788-1808). Actas del IV Congreso Internacional de la SEES XVIII, Oviedo, Instituto Feijoo-SEESX- 
Jaén y Córdoba), se fundaron en ciudades y villas como Baeza, Baza, Cabra, Málaga, Montilla, Motril, Priego, Puerto de Santa María, Sanlúcar o Vélez Málaga ${ }^{18}$.

En Castilla y León hubo más de 20, algunas en capitales de provincia (Ávila, Burgos, León, Palencia, Segovia, Valladolid), otras en poblaciones de menor entidad (Alba de Tormes, Benavente, Ciudad Rodrigo, Herrera del Pisuerga, La Bañeza, Medina del Campo y Medina de Rioseco, Ponferrada, Tordesillas) ${ }^{19}$. Alrededor de una docena hubo en Castilla la Mancha, tanto en las ciudades más importantes, como en poblaciones más pequeñas: Cuenca, Chinchón, Ocaña, San Clemente, Sigüenza, Talavera, Toledo, Valdepeñas, Yébenes ${ }^{20}$. Tres funcionaron en Extremadura, en Coria, Plasencia y Trujillo ${ }^{21}$. Tampoco faltaron Económicas en Canarias, concretamente en Las Palmas, La Laguna, La Palma y San Sebastián de la Gomera ${ }^{22}$. Por último, hay que destacar que entre 1781 y 1810 se crearon una docena de Sociedades en distintos puntos del imperio español. La primera se fundó en Manila, el resto son americanas, destacando las de Santiago de Cuba, La Habana, Lima, Quito, Nueva Granada, Guatemala, Sta. Fe de Bogotá y Caracas ${ }^{23}$.

VIII-SECC, 2009, pp. 483-495; FORNIES CASALS, J.F.: La Real Sociedad Económica Aragonesa de Amigos del País, Madrid, CECA, 1978; DEMERSON, P.: Próspera y adversa fortuna de la Real Sociedad Cantábrica (1775-1804), Santander, Institución Cultural de Cantabria, 1986; DOPICO, F.: "As Sociedades Económicas de Amigos do País", en A Ilustración..., op. cit., pp. 51-64 y FRAGUAS FRAGUAS, A.: Real Sociedad Económica de Amigos del País de Santiago: primera época, 1784-1813-1821, [Santiago de Compostela], Grafisant, [2008]; BORRELL MERLÍN, M.D.: La Sociedad Económica de Cosecheros del País de la Rioja (1783-1833), Madrid, Universidad Complutense, 1991; LLABRES BERNAL, J.: "La Real Sociedad Económica Mallorquina de Amigos del País", Boletín de la Real Sociedad Arqueológica Luliana, XXXIII (1971), pp. 380-391; VELÁZQUEZ MARTÍNEZ, M.: La Sociedad... Murcia, op. cit.; ALEIXANDRE TENA, F.: La Real Sociedad Económica de Amigos del País de Valencia: marco jurídico, estructura social y financiación (1776-1833), Valencia, Sociedad Económica de Amigos del País, 1983 y LÓPEZ TORRIJO, M.: Educación y sociedad en la Valencia ilustrada: labor educativa de la Real Sociedad Económica de Amigos del País de Valencia (1776-1808), Valencia, Nau Llibres, 1986.

18 ARIAS DE SAAVEDRA ALÍAS, I.: "Las Sociedades Económicas de Amigos del País en Andalucía", Chronica Nova, 28 (2001), pp. 9-47. Sobre las del antiguo Reino de Granada: CASTELLANO CASTELLANO, J.L.: Luces y reformismo. Las Sociedades Económicas de Amigos del País del Reino de Granada en el siglo XVIII, Granada, Diputación, 1984.

19 ENCISO RECIO, L. M.: "Las Sociedades Económicas castellano-leonesas: Apunte institucional y sociológico", en Perspectivas de la España Contemporánea. Estudios en homenaje al profesor $V$. Palacio Atard, Madrid, 1986, pp. 21-46 y GONZÁLEZ MARTÍNEZ, R.M.: La Real Sociedad Económica de Amigos del País de León, León, Caja de Ahorros, 1981.

20 BARREDA FONTES, J.M. y CARRETERO ZAMORA, J. M.: Ilustración y reforma en la Mancha: Las Reales Sociedades Económicas de Amigos del Pais, Madrid, CSIC, 1981.

21 DEMERSON, P.: "Las Sociedades Económicas de Extremadura en el siglo XVIII", Revista de Estudios Extremeños, t. XXVIII, 3 (1972), pp. 579-596.

22 GARCÍA DEL ROSARIO, C.: La Real Sociedad Económica de Amigos del País de las Palmas de Gran Canaria, Las Palmas, Mancomunidad de Cabildos, 1982; ROMEU PALAZUELOS, E.: La Real Sociedad de Amigos del País de Tenerife, Las Palmas, Mancomunidad de Cabildos, 1979; PAZ SÁNCHEZ, M.: Los amigos del Pais de la Palma. Siglos XVIII y XIX, Las Palmas, Idea, 2006.

23 SHAFER, R. J.: The Economic Societies in the Spanish World (1763-1821), Syracuse, University Press, 1958. 
La historiografía sobre estos institutos ha destacado la ausencia de Económicas en las ciudades peninsulares con los núcleos burgueses más activos, como Barcelona, Cádiz, La Coruña o Bilbao, concluyendo que no eran los burgueses los promotores de estas instituciones. La mejor situación económica de estas ciudades y la existencia de instituciones de objetivos parecidos a las Económicas, como los consulados de comercio, harían innecesarias estas fundaciones ${ }^{24}$. Estos razonamientos no parecen del todo convincentes y pecan de un cierto economicismo. Santander y Málaga eran ciudades con burguesía donde se simultanearon consulados y Económicas, y en Cádiz terminaría habiendo una, aunque en fecha más tardía ${ }^{25}$.

Pocas veces se denegó el permiso de creación. El Consejo mantuvo el principio de que "la mera comunicación de las luces" sería beneficiosa para sus afiliados. Tan solo no aprobó fundaciones en San Sebastián y Burgos, por oponerse la Bascongada y el Consulado respectivamente, aunque esta última se constituiría en $1816^{26}$. También denegó la autorización a Vara del Rey, Ágreda y Villafranca de los Barros, por ser lugares pequeños. Otras Económicas autorizadas no llegarían a aprobar estatutos.

\section{Composición social}

Sobre la composición social de las Económicas se ha escrito bastante y casi todos los estudios concretos prestan atención a este asunto. Su promotor, Campomanes, dirigió esta iniciativa "a la nobleza, al clero y a las gentes acomodadas". Sarrailh señaló la coincidencia de todos los grupos sociales dentro de las Económicas, y en el mismo sentido insiste Gonzalo Anes en sus trabajos, destacando que las reformas promovidas por ellas beneficiarían de modo muy especial a los rentistas (nobleza y al clero), pero también a los demás sectores productivos: campesinos, artesanos, trabajadores de las ciudades, etc., lo que explicaría la presencia de todos ellos en sus filas ${ }^{27}$.

Los estudios sociológicos se han basado sobre todo en el análisis de las listas de socios, especialmente en el momento de constitución de las Sociedades, fuente relativamente frecuente. En los institutos con una documentación más completa, se ha eva-

24 LLUCH, E.: "El caso de la no fundación de la Sociedad Económica de Amigos del País de Barcelona”, Revista de Occidente, 115 (1970), pp. 51-70 y ANES, G.: “Coyuntura...”, art. cit., p. 26.

25 LÓPEZ MARTíneZ, A.: La Sociedad Económica de Amigos del País de Málaga, Málaga, Diputación de Málaga, 1987; OROZCO ACUAVIVA, A.: "La Real Sociedad Económica de Cádiz", en La burguesía mercantil gaditana, 1650-1868, Cádiz, Instituto de Estudios Gaditanos, 1976, pp. 263-273 y MARTÍN FERRERO, P.: La Real Sociedad Económica Gaditana de Amigos del País, Cádiz, 1988.

26 BALlESTEROS CABALlERO, F., La Sociedad Económica de Amigos del País de Burgos, Burgos, 1983.

27 CAMPOMANES, P.R. de: Discurso sobre el fomento..., op. cit., pp. 103-104; SARRAILH, J.: La España..., op. cit., p. 230; ANES, G.: “Coyuntura...", art. cit., p. 22. 
luado la asistencia a las juntas, pues algunos promotores tuvieron una participación muy escasa en las labores de la sociedad. Luis Miguel Enciso, basándose en las monografías sobre estos cuerpos, apunta una síntesis sobre la "sociografía" de las Económicas. El conjunto de los estudios realizados hasta ahora señalan un amplio espectro social en sus filas. En todas hay, en mayor o menor medida, nobles, eclesiásticos, personal de la administración, militares, hacendados e incluso algunos burgueses (comerciantes, artesanos y fabricantes). La composición social concreta varía en cada caso y tiene mucho que ver con la sociedad local en que la Económica se ubica ${ }^{28}$.

La presencia de la nobleza está bien documentada entre los promotores de la Bascongada, como ya se ha señalado. En algunos casos, como en Baeza, el protagonismo de la nobleza es muy marcado, como corresponde a una pequeña ciudad de cuño aristocrático, como era la ciudad jiennense. Otro ejemplo de fundación temprana, la Económica de Sevilla, presenta también un alto protagonismo nobiliario en sus filas, aunque agrupa a otros elementos representativos de la sociedad hispalense. Sus promotores intentaron hacer de este instituto un coto cerrado de la nobleza. En su primer proyecto de estatutos, que no sería aprobado, se limitó el número de socios a cuarenta, de los cuales la mitad deberían de ser nobles con patrimonio y renta en Sevilla y el resto cargos públicos o personajes de reconocida categoría intelectual ${ }^{29}$.

También era muy significativa la nobleza en la Sociedad de Segovia, donde este estamento alcanzaba un veinte por ciento de sus promotores -proporción solo inferior al grupo de personal de la administración y profesiones liberales-, en la de Valladolid, donde alcanzaba una proporción superior al 15 por ciento del total, y era menor en otros Sociedades como la Aragonesa, donde la nobleza titulada suponía algo más del diez por ciento de los socios. En general, buena parte de la aristocracia local se afilió en las Económicas, aunque no siempre estuvo entre sus miembros más activos ${ }^{30}$.

Es destacable el interés de algunos grandes señores de la aristocracia en promover la creación de Económicas en sus estados. Así la de Osuna nació a partir de una

28 ENCISO RECIO, L. M.: "La burguesía y las Sociedades Económicas”, en La burguesía española en la Edad Moderna. Actas Congreso Internacional, Valladolid, Universidad, 1996, t. III, pp. 79-162, recogido en Las Sociedades... op. cit., pp. 179-283.

29 AGUILAR PIÑAL, F.: "Fundación de la Sociedad Patriótica de Sevilla", en Temas sevillanos (Primera serie), Sevilla, Gráficas Oviedo, 1972, pp. 77-93 y ARBOLI IRIARTE, M.D.: "Los orígenes de la Real Sociedad Económica sevillana de Amigos del País (1775-1778), en I Congreso de profesores investigadores. I. H. ${ }^{a}$ de Andalucía, Sevilla, 1984, pp. 149-168.

30 MELÉNDEZ GALLOSO, A.: "Sociografía de los Amigos del País de la Real Sociedad Económica de la provincia de Segovia", Coloquio Internacional sobre Carlos III y su siglo, Madrid, 1990, t. II, pp. 841-850; DEMERSON, J.: La Real Sociedad Económica de Valladolid, 1784-1808, Valladolid, 1969, p. 41; FORNIÉS CASALS, J.F.: "La estructura social de los Amigos del País de Aragón”, en Boletín de documentación del fondo para la investigación económica y social, vol. IX (1977), pp. 285-308. 
tertulia, que se transformó en Económica bajo la protección de los duques de la villa. En Cabra se creó una Sociedad promovida por el marqués de Astorga y Conde de Altamira, que sería además el primer director, y La Sociedad de Aguilar de la Frontera fue promovida y protegida por el duque de Medinaceli ${ }^{31}$.

En otros casos el protagonismo del clero fue muy destacable. Es lo que ocurre en algunas Sociedades andaluzas, como por ejemplo, en la Sociedad Patriótica de Vera, que en el año de su fundación contaba con un tercio de miembros eclesiásticos, y más aún en la Económica de Jaén, donde más de la mitad de sus fundadores eran clérigos, del cabildo catedralicio y de las órdenes religiosas con implantación en la ciudad. Esta Sociedad estuvo promovida por el obispo de la diócesis, lo mismo que las de Puerto Real y Medina Sidonia ${ }^{32}$. También tuvieron promotores eclesiásticos las de Motril, Almuñécar, Alcalá la Real, Córdoba, y Vélez Málaga ${ }^{33}$. Fuera de Andalucía el peso clerical también fue muy fuerte: la Sociedad de Cuenca fue promovida por el obispo de la diócesis y en el momento de su fundación eran eclesiásticos la mitad de sus miembros. También fue grande la presencia clerical en la Económica de Zaragoza, una cuarta parte de sus socios eran eclesiásticos, el sector más numeroso. Otros ejemplos del interés del clero por las Económicas podrían ponerse. Entre 1770 y 1786, por ejemplo, la Bascongada tenía 96 miembros eclesiásticos y en 1789 cinco obispos y un fraile eran directores de Económicas, entre ellos una personalidad tan relevante como el obispo Francisco Armañá que dirigía la Económica de Tarragona ${ }^{34}$.

Es también destacable el peso que en las Económicas tienen los funcionarios, empleados de la administración y militares. El caso más paradigmático es el de la Sociedad Matritense; entre sus primeros socios el grupo más abundante son los funcionarios, que superan una tercera parte, destacando entre ellos personalidades como los Secretarios del Despacho de Indias y Hacienda, un gobernador del Consejo y 26 consejeros (de Castilla, Indias, Hacienda, Guerra e Inquisición), secretarios de varios

31 SORIA MEDINA, E.: La Sociedad Económica de Amigos del País de Osuna, Sevilla, Diputación Provincial, 1975; GARCÍA GARCÍA, J.: "Real Sociedad Económica de Amigos del País de Cabra (Córdoba)", en Actas I Congreso de Historia de Andalucia. Andalucia Moderna (Siglo XVIII), Córdoba, 1978, t. I, pp. 221-227 y GAY ARMENTEROS, J. y VIÑES MILLET, C.: La Ilustración andaluza, Barcelona, Editoriales Andaluzas Unidas, 1985, p. 128.

32 DEMERSON, J. y P.: "La Sociedad Patriótica de Vera y su jurisdicción (1775-1808)", Anuario de Historia Moderna y Contemporánea, 11 (1984), pp. 5-98; ARIAS DE SAAVEDRA ALÍAS, I.: Las Sociedades...Jaén, op. cit., pp. 206-208; FRANCO RUBIO, G. A.: "La re-construcción de la sociabilidad ilustrada: Las Sociedades gaditanas de Amigos del País", De mentalidades y formas culturales en la Edad Moderna. Cuadernos de Historia Moderna. Anejos, I (2002), pp. 177-209.

33 DEMERSON, P. y J.: "La Sociedad Económica y Patriótica de Vélez Málaga. Notas para su historia”, Anuario de Historia Moderna y Contemporánea, 4-5 (1977-1978), pp. 87-190.

34 SÁNCHEZ REAL, J.: La Sociedad Económica de Amigos del País de Tarragona, Tarragona, 1972. 
consejos y otros altos funcionarios ${ }^{35}$. También fue muy fuerte la presencia del personal de la administración en la Sociedad Aragonesa, con valores cercanos a una cuarta parte del total de sus miembros.

En algunas ocasiones fueron agentes del poder real los promotores de las Económicas, como ocurre con los corregidores de Plasencia, Lucena, Guadix y Quesada, que impulsaron Económicas en sus villas ${ }^{36}$. El entendimiento y colaboración con los cuadros de la administración local facilitó el buen funcionamiento, cuando la colaboración faltó todo fueron problemas. Buen ejemplo es el caso de Granada, donde la fundación de la Económica tuvo que sortear la oposición de un sector del ayuntamiento. Aunque por lo general con una significación menor, también fue obligada la presencia de militares, los afincados en las respectivas zonas nunca solían faltar en estos institutos.

Una cuestión fuertemente debatida por la historiografía es la presencia de la burguesía en las filas de las Económicas. La presencia de la burguesía en sentido estricto (comerciante e industrial) no tuvo mucha relevancia, pues en nuestro país era entonces poco significativa y en amplias zonas prácticamente inexistente. De todos modos hay una cierta presencia burguesa en las Sociedades de ciudades periféricas, o en la de la capital. Ya se ha señalado la capacidad integradora de la Bascongada respecto a los núcleos burgueses de San Sebastián y Bilbao, lo mismo ocurrió con la Sociedad de Málaga, respecto a los comerciantes de su ciudad. En la Matritense el peso de comerciantes, diputados de gremios o artesanos, alcanza solo a poco más de la décima parte de los socios. Una de las Económicas donde este sector es más fuerte es la de Segovia, fabricantes y artesanos significaron entre el 15 y el 20 por ciento del total de los socios. De todos modos, los valores de este sector no solían ser dominantes. El resto de los componentes de las Económicas son hacendados y profesiones liberales que, en mayor o menor medida, casi siempre tienen en ellas alguna representación.

En definitiva, la estructura social de las ciudades sede fue determinante a la hora de configurarse las Económicas. Los sectores sociales más relevantes asumieron un especial protagonismo. Aunque no fueran creaciones típicamente burguesas, puede rastrearse en ellas una cierta conciencia burguesa, es decir, sus miembros participaron en una cierta mentalidad burguesa.

35 CILlÁN OTERO, F.: La Real Sociedad Económica Matritense y las reformas de Carlos III. Tesis doctoral inédita, Madrid, 1990.

36 ABRÁS SANTIAGO, J.A.: "La Real Sociedad Laboriosa de la M. N. y M. L. ciudad de Lucena (1762)", en Actas I Congreso de Historia de Andalucía. Andalucía Moderna (Siglo XVIII), Córdoba, 1978, t. I, pp. 3-12 y ARIAS DE SAAVEDRA ALÍAS, I.: "El intento de crear una Sociedad Económica en Quesada", Chronica Nova, 12 (1981), pp. 7-21. 


\section{Las mujeres y las Económicas}

La posible participación de las mujeres en las Sociedades se planteó por primera vez en 1775, en el seno de la recién creada Sociedad Económica Matritense ${ }^{37}$. Durante más de diez años fue objeto de un arduo debate que enfrentó a partidarios y detractores de la presencia femenina ${ }^{38}$. Entre los defensores destaca Campomanes, que expresó su opinión favorable a través de una memoria leída en la Matritense en noviembre de 1775. El fiscal del Consejo de Castilla era partidario de la entrada en condiciones de igualdad con los varones, sin limitación de número, con obligación de satisfacer cuotas y con derecho a participar en las juntas, para ocuparse de tareas como el cuidado de las escuelas patrióticas ${ }^{39}$. No sería su opinión la que acabaría por imponerse. En el bando de los partidarios se sitúan también los socios José Marín, Luis de Imbille y Jovellanos ${ }^{40}$, que recibieron también el apoyo de una mujer, Josefa Amar Borbón. La voz de los detractores la tomó Cabarrús. La polémica se zanjó, por fin, en 1787, por medio de una orden del rey que creaba la Junta de Damas de las Sociedad Económica Matritense, formada inicialmente por catorce socias de honor y mérito, que comenzaría a funcionar como una sección aneja a la Sociedad en octubre de este mismo año, dotándose de sus propios estatutos, aprobados por el rey en 1794. Las mujeres, por tanto, no entraron como socias de la Económica, sino de un organismo paralelo, con funciones específicas y muy concretas.

La Junta agrupó a una importante elite madrileña, con destacadas personalidades de la nobleza: las duquesas de Osuna y Almodóvar, las condesas de Fernán Núñez, Montijo, Benalúa, Santa Eufemia, Carpio, las marquesas de Palacios, Ayerbe, Villalópez y Torrecilla, así como otras personalidades de la sociedad capitalina ${ }^{41}$. Todas eran madrileñas, excepto Josefa Amar Borbón, residente en Zaragoza, que fue admitida en la Económica en reconocimiento a su participación en la polémica sobre

37 ARIAS DE SAAVEDRA ALÍAS, I.: "Las Sociedades Económicas de Amigos del País y la mujer”, en CALDERÓN ESPAÑA, Mª C.: Las Sociedades Económicas de Amigos del País y el espíritu ilustrado, Sevilla, Real Sociedad Económica, 2001, pp. 163-179.

38 Sobre la polémica: DOMERGUE, L.: Jovellanos à la Societé Économique des Amis du Pays de Madrid 1778-1795, Toulouse, France-Ibérie, 1971, pp. 233-266; AGUILAR PIÑAL, F.: "La Real Sociedad Económica Matritense de Amigos del País”, Instituto de Estudios Madrileños, no 3 (1972), pp. 15-18 y FERNÁNDEZ QUINTANILLA, P.: La mujer ilustrada en la España del siglo XVIII, Madrid, Subdirección General de la Mujer, 1981. Las distintas opiniones en NEGRIN FAJARDO, O.: Ilustración y educación. La Sociedad Económica Matritense, Madrid, Editora Nacional, 1984, pp. 131-183.

39 CAMPOMANES, Conde de: Memoria sobre la admisión de señoras... Madrid, 18 de noviembre de 1775 .

40 NEGRÍN FAJARDO, O.: "La posición de Jovellanos en el debate para la admisión de mujeres en la Real Sociedad Económica Matritense de Amigos del País”, CEES XVIII, 21 (2011), pp. 149-171.

41 DEMERSON, P.: "Catálogo de las socias de honor y mérito de la Junta de Damas (1787-1811)", Anales del Instituto de Estudios Madrileños, VII (1971), pp. 269-274. 
la admisión femenina, y Madame Le Masson le Goft, residente en El Havre. El número de damas de la Junta se limitó a cuarenta. Entre 1787 y 1800 formaron parte de ella 78 socias, pero el alma de la Junta fue el cuarteto formado por la primera directora, la condesa de Benavente y duquesa de Osuna, la secretaria, condesa de Montijo y por las condesas de Trullas y de Sonora. A estas cuatro mujeres están ligadas las iniciativas más relevantes de la Junta de Damas y fueron ellas quienes más trabajaron, asistiendo a reuniones y desempeñando las tareas cotidianas de la corporación.

$\mathrm{Su}$ actuación se ciñó a tareas que se consideraron más apropiados de la actuación femenina, como la enseñanza y la beneficencia. En el campo educativo dirigieron las cuatro escuelas patrióticas, creadas por la Matritense a poco de su fundación, y una escuela de bordado de su propia iniciativa. En materia de beneficencia sobresale la actuación de la condesa de Montijo a cargo de la inclusa de Madrid, con una notable mejora de la gestión de este centro, que conllevó una importante disminución de la mortalidad infantil. También por su iniciativa promovió la Asociación de Presas de la Galera, para ayudar a las reclusas a regenerarse por medio del trabajo, creando una enfermería para atender a las presas embarazadas y trabajando para evitar abortos e infanticidios ${ }^{42}$.

La Sociedad Económica Matritense fue la única que, a lo largo de la etapa que nos ocupa, llegó a articular la participación de las mujeres en su instituto, si bien no dentro de él propiamente. En otras Sociedades, como las de Zaragoza y Jaén, aunque se produjeron algunas iniciativas, no llegó a cuajar la entrada de mujeres, ni siquiera en una junta separada. Lo que sí se produjo en algunas Económicas fue la excepcional entrada de alguna mujer en la categoría de socios honorarios. Así, en la Sociedad Matritense, antes de la creación de la Junta de Damas, se admitieron como socias honorarias a la condesa de Benavente y a Isidra Quintina de Guzmán, primera mujer que se graduó como doctora en la Universidad de Alcalá, que sería también honoraria de la Bascongada. Y en la de Zaragoza sería admitida, entre otras, Josefa Amar Borbón, una de las mujeres más relevantes de la ilustración española, gran defensora de la capacidad intelectual femenina y del valor de la educación ${ }^{43}$.

También hubo socias honorarias en Económicas más provincianas, como las de Ciudad Rodrigo, Murcia o Granada. La presencia de mujeres como socias honorarias de las Económicas fue poco relevante. Las admitidas eran siempre personalidades importantes, con frecuencia ligadas a cargos directivos, que muy poca labor

42 DEMERSON, P.: "La real inclusa de Madrid a fines del siglo XVIII", Anales del Instituto de Estudios Madrileños, VIII (1972), pp. 261-272 y de la misma autora: María Francisca de Sales Portocarrero (condesa de Montijo). Una figura de la Ilustración, Madrid, Editora Nacional, 1975, pp. 215-244.

43 LÓPEZ-CORDÓN CORTEZO, M.V.: Condición femenina y razón ilustrada: Josefa Amar Borbón, Zaragoza, Prensas Universitarias de Zaragoza, 2005 
desempeñaron y cuya presencia no pasó de ser testimonial. Si parece algo más efectiva la colaboración prestada por otras mujeres, casi siempre familiares de socios, en tareas como la adjudicación de premios a labores, hilazas, confección de cintas, blondas, etc., o al examen de niñas de las escuelas patrióticas y de sus maestras. En las actas y memorias de las Sociedades de Jaén, Granada, Sevilla, o Valladolid, aunque seguramente fueron más, se conservan testimonios de estas actuaciones, siempre al margen de cualquier institucionalización.

\section{El modelo organizativo}

En el aspecto institucional cabe señalar dos modelos en las Sociedades Económicas de Amigos del País, representados por la Bascongada y por la Sociedad Matritense. El primero es mucho más complejo y se adecua a la necesidad de agrupar en una sola institución a los amigos del país de las tres provincias vascas, acercándose en su configuración a los organismos forales, constituyéndose como un órgano de consulta de estos; por eso la Bascongada se desdobla en tres secciones, una por provincia, estructuradas en comisiones de trabajo. Todas las secciones se reunían anualmente en las Juntas Generales, que se celebraban alternativamente en cada una de las tres sedes: Vergara, Bilbao y Vitoria. La estructuración en cuatro comisiones -Agricultura, Ciencias y Artes útiles, Industria y comercio, e Historia, política y buenas letras-, demuestra también una cierta complejidad y una fuerte preocupación por los problemas culturales. También fue compleja la tipología de sus socios: de número, supernumerarios, veteranos y beneméritos, con un nivel de compromiso diferente, además de miembros literarios, profesores y alumnos, relacionados con las labores docentes. Otra peculiaridad era la existencia de número clausus entre sus miembros más activos. La sociedad estaba constituida por 24 socios de número, ocho por cada una de las provincias, que eran los encargados de dirigirla. Ellos copaban los cargos: director, dos consiliarios o directores provinciales, secretario general, tres vigiladores o secretarios provinciales, responsables de la educación de los alumnos, un recaudador general y tres recaudadores provinciales ${ }^{44}$.

Esta complejidad de la sociedad pionera se perderá en el resto de las Económicas. Los estatutos de la Bascongada no inspirarán a los institutos nacidos tras el impulso de Campomanes. Tan solo en las más tempranas tendrán una cierta influencia. La

44 Complejidad plasmada tanto en los estatutos primitivos, como en los definitivamente aprobados en 1772: Estatutos de la Sociedad Bascongada de los Amigos del País, según el acuerdo de las Juntas de Vitoria por abril de 1765, San Sebastián, Imprenta de L. J. de Riesgo, s.a. [1765] y Estatutos aprobados por S. M. para el gobierno de la Real Sociedad Bascongada de los Amigos del País, Vitoria, Imprenta de Tomás de Robles, s. a., [1773]. 
Económica de Baeza es la única que se inspira propiamente en la Económica vasca. Sus estatutos, aunque menos complejos, conservan algunos de sus rasgos: fijación de los numerarios en 36, proliferación de hasta seis tipos de socios distintos -numerarios, supernumerarios, honorarios, beneméritos, profesores y alumnos-, así como estructuración de las tareas en cuatro comisiones de trabajo -Erudición varia y bellas letras, Economía rústica y cría de ganados, Ciencias y artes útiles, e Industria y comercio-, todos ellos copiados de la organización vasca ${ }^{45}$. También en su primer proyecto de estatutos la Patriótica de Sevilla presentaba un número de socios cerrado y de compleja jerarquía -numerarios, correspondientes, supernumerarios, honorarios y jóvenes-. No en vano esta Económica fue promovida, entre otros, por un nutrido grupo de vascos afincados en esta ciudad, socios de la Bascongada, lo mismo que el Asistente, Pablo de Olavide, su principal promotor ${ }^{46}$.

Salvo estas excepciones, las Económicas se adecuaron al modelo diseñado por Campomanes en su Discurso sobre el fomento de la industria popular, que tendría su plasmación más acabada en los estatutos de la Matritense ${ }^{47}$. Todas las Económicas, en el momento de su constitución, recibían un ejemplar de los estatutos madrileños como modelo para redactar los suyos, cuya aprobación necesitaba el dictamen del censor de la Matritense. Así este organismo se transformó en rector de todas las Económicas. Por esta razón, todas ellas fueron bastante similares, salvando las distancias entre Sociedades de ciudades importantes, con un número de socios elevado y una relevante actividad y las de pequeños pueblos, con pocos socios y modestas realizaciones.

Las Sociedades Económicas se configuraron como organismos que comprendían un número indeterminado de socios numerarios, sin especiales requisitos salvo el pago de cuotas y la residencia en la ciudad sede, que realizaban las tareas de la Sociedad, además de socios correspondientes, con residencia fuera de la ciudad, y socios agregados, labradores, fabricantes y artesanos con labores de asesoramiento, que ocupaban una posición más secundaria. Para su gobierno y dirección solían tener los siguientes oficiales: director, secretario, censor, contador y tesorero, todos ellos electivos, con un tiempo de permanencia en los cargos variable, aunque fueron frecuentes las reelecciones.

45 Estatutos provisionales de la Junta preparatoria de la Sociedad de Verdaderos Patricios de Baeza y Reyno de Jaén, Madrid, Imprenta de Andrés Ramírez, 1775.

46 AGUILAR PIÑAL, F.: "Sevilla y los caballeritos de Azcoitia", en Temas sevillanos..., op. cit., pp. 73-76.

47 Real Cédula de S. M. y señores del Consejo en que se aprueban los estatutos de la Sociedad Económica de Amigos del País, con lo demás que se expresa, a fin de promover la agricultura, industria y oficios, Madrid, Imprenta de Sancha, 1775. 
Para desarrollar sus tareas los socios solían distribuirse en comisiones. En la Matritense su número se redujo a tres: Agricultura, Industria y Artes, al desaparecer la cuarta comisión, más teórica y especulativa, que existía en la Bascongada. Esta distribución sería la más generalizada, al ser los estatutos de muchas Sociedades una mera copia de los de Madrid. No obstante, hubo Sociedades donde el número de comisiones se multiplicó, sin que por ello se consiguiera una mayor eficacia, pues tal proliferación podía hacerlas inoperantes (Vera con doce comisiones o Jaén con diez). Las comisiones eran la auténtica médula de las Económicas, llevaban a cabo las tareas del instituto. Y se reunían semanalmente.

Además había otras juntas de todos los miembros de la Sociedad, que solían tener periodicidad mensual, y unas juntas públicas de carácter anual, más solemnes, celebradas generalmente la festividad de S. Carlos, con asistencia de personalidades ajenas a las Sociedades, donde se daban a conocer al público las realizaciones de las Económicas, se adjudicaban premios, se examinaba a los alumnos, etc. Muchos institutos publicaron reseñas de estas reuniones en la prensa del momento, especialmente en la Gaceta y en el Mercurio de Madrid. Estas reseñas son una fuente inestimable para el estudio de las actividades de estas corporaciones, especialmente en aquellas que no editaron memorias.

\section{Realizaciones de las Sociedades Económicas}

Según las directrices de Campomanes en su Discurso sobre el fomento de la industria popular y en escritos posteriores, las Económicas habrían de ser unas instituciones, hasta entonces inexistentes, que informaran al gobierno sobre la situación económica y social de los diversos territorios, para sobre esta base aplicar el programa de reformas gubernamental. Se conciben, por tanto, como órganos consultivos del gobierno $^{48}$. Campomanes desarrolla en una docena de puntos las tareas que han de llevar a cabo. En el plano local o regional, deben "fomentar el estado de la provincia", informando sobre su población y actividades económicas. Respecto a la primera, remitirán al Consejo estadísticas anuales, con especial atención a los marginados (vagos, mendigos, emigrantes). Respecto a la economía, se interesarán por la agricultura, cría de ganados, pesca, manufacturas, fábricas, comercio y navegación. Se ocuparán de los aspectos teóricos, con especial atención a la lectura de obras económicas, incluso extranjeras, y a experimentos y cálculos políticos, pero también de los aspectos prácticos de estas actividades. En el ámbito nacional supervisarán los proyectos económicos, ayudando en su depuración y rectificación, si fuera necesario. Deberán interesar-

48 ENCISO RECIO, L. M.: “Las Sociedades”, art. cit., p. 34. 
se también por fomentar la educación, tanto de la nobleza como del pueblo, base del desarrollo económico. Como muy bien lo expresó Paula Demerson, las Sociedades Económicas de Amigos del País representaron ante la administración el papel de un "consejo técnico" que nació con un doble objetivo: difundir la enseñanza útil y racionalizar la economía ${ }^{49}$.

Los estatutos recogen, con ligeras variantes, de forma expresa estas funciones a la hora de definir los objetivos de las Sociedades. Así, por ejemplo, los Estatutos de la Matritense, en sus artículos segundo y tercero de su título primero dicen: "Su instituto es conferir y producir las memorias para mejorar la industria popular y los oficios, los secretos de las artes, las máquinas para facilitar las maniobras y auxiliar la enseñanza" y añaden: "El fomento de la agricultura y la cría de ganados, será otra de sus ocupaciones, tratando por menor los ramos subalternos relativos a la labranza y la crianza". Veremos a continuación hasta qué punto cumplieron estos objetivos.

\section{La enseñanza}

Una de las más importantes misiones de las Sociedades Económicas era el fomento de la educación y quizá fue éste el campo en el que tuvieron éxitos más palpables. Dentro de la mentalidad ilustrada se consideraba la educación como requisito indispensable para elevar el nivel de vida material y moral de la población. Como señalara Carande, son precedentes del programa regeneracionista que con el lema “despensa y escuela” intentó transformar la sociedad española un siglo más tarde ${ }^{50}$. Muchos de los lemas adoptados por ellas aluden precisamente a su labor educativa, por ejemplo el de la Matritense: "socorre enseñando", que inspiraría lemas de sociedades posteriores, como el de Aguilar de la Frontera, "favorece instruyendo", o el de La Bañeza: "Aprendo y soy socorrido" ${ }^{51}$. Téngase en cuenta la deficiente situación educativa en la España del siglo XVIII, cuando la enseñanza no era considerada aún un servicio público. Durante el reinado de Carlos III el gobierno comenzó una serie de actuaciones encaminadas a mejorar el panorama educativo, en este campo se inscribe la actuación de las Sociedades Económicas de Amigos del País que desempeñaron una importante aportación sobre todo en los niveles más elementales de la enseñanza. Los ilustrados consideraban que la enseñanza no debía ser universal y ho-

49 CAMPOMANES, P. R. conde de: Discurso sobre el fomento..., op. cit., pp. 104-107 y DEMERSON, P.: "Las escuelas patrióticas de Madrid entre 1787 y 1808”, en Las Reales Sociedades Económicas de Amigos del País y su obra, San Sebastián, CSIC, 1972, p. 191.

50 CARANDE THOVAR, R.: "El despotismo ilustrado...”, art. cit., pp. 169-170.

51 MARTÍ, M.: "Emblemas y lemas de las Sociedades Económicas de Amigos del País. Análisis de un discurso de intenciones”, Brocar, 19 (1995), pp. 189-209 y GONZÁLEZ ECHEGARAY, C.: Los emblemas de las Sociedades Económicas de Amigos del País, San Sebastián, Real Sociedad Vascongada de Amigos del País, 1999. 
mogénea, sino que debía ser distinta según la clase social a la que iba destinada. Por eso las Económicas mantuvieron una clara diferenciación entre la educación de la juventud noble y clases altas, llamadas a ser las rectoras del país, y la educación de las clases populares, entre las que interesaba difundir los conocimientos útiles, condición indispensable para lograr el desarrollo económico.

Ya nos hemos referido a la creación del Seminario de nobles de Vergara, destinado en principio a los hijos de la nobleza vasca, aunque después su base social se amplió considerablemente. En la misma línea, las Económicas intentaron crear bajo su supervisión una red de seminarios de nobles en las ciudades más importantes del país, con unos contenidos docentes muy ambiciosos -idiomas, ciencias, economía, etc.-, pero este proyecto no llegó a hacerse realidad. También fracasaron los intentos de crear seminarios de nobles de las Económicas de Sevilla, Granada o Vera ${ }^{52}$.

Fue en la educación popular el campo donde más importante acción desempeñaron las Económicas. Incluso las establecidas en los pueblos más pequeños y con menos recursos adoptaron a este respecto iniciativas importantes. En la enseñanza de primeras letras, uno de sus principales objetivos, el nivel más simple de actuación fue intervenir sobre los centros educativos ya existentes, incentivando a los niños y maestros por medio de premios. En casi todas las Económicas hallamos estos premios en metálico, que podían estimular una enseñanza muy mal pagada. También en algún caso, cómo en Sevilla, la Económica intentó controlar el acceso a la docencia, creando un Colegio Académico, a imitación del existente en Madrid, que examinara a los aspirantes a maestros ${ }^{53}$.

En otros casos las Económicas crearon sus propios centros educativos, escuelas de primeras letras dirigidas a los niños - como en el caso de Vera, Cabra o Lucena- y las llamadas "escuelas patrióticas" para las niñas, uno de sus logros más importantes. En este campo, como en tantos otros, la pionera fue la poderosa Sociedad Matritense, que en sus estatutos ya contemplaba estos centros. A mediados de 1776 abrió cuatro escuelas patrióticas, sostenidas con una asignación real y con fondos de la lotería, que inicialmente debían impartir de forma gratuita enseñanza separada a niños y niñas, pero pronto se destinaron exclusivamente a la enseñanza femenina. Los alcaldes de barrio velaban por el reclutamiento de las alumnas. En ellas se enseñaba a las niñas las técnicas del cardado, la fabricación de hilazas de lino, algodón, lana. Eran centros

52 AGUILAR PIÑAL, F.: "Los reales seminarios de nobles en la política ilustrada española", Cuadernos Hispanoamericanos, 356 (1980), pp. 329-349.

53 AGUILAR PIÑAL, F.: "La Sociedad Económica de Sevilla en el siglo XVIII ante el problema docente", en Las Reales Sociedades Económicas de Amigos del País y su obra, San Sebastián, CSIC, 1972, pp. 317-336. 
orientados a la enseñanza de los oficios, aunque más tarde se ampliaron a doctrina cristiana y primeras letras. El producto obtenido por la venta de los trabajos se destinaba a la compra de materias primas y material. De la docencia se encargaban maestras seleccionadas tras un riguroso examen y en la década final de siglo contaban con la colaboración de ayudantes. Creada la Junta de Damas, le fue encomendado el cuidado de las escuelas. Las señoras de la Matritense dotaron a las escuelas de un reglamento, aprobado por la Sociedad en 1792, que mejoró las enseñanzas y les dio nuevo impulso, prestando mayor atención a la enseñanza de primeras letras por el método Anduaga. Pese a los problemas económicos, las escuelas patrióticas de Madrid lograron sobrevivir hasta 1811. El número de alumnas previsto inicialmente de 120 fue ampliamente rebasado en la práctica. En 1797 asistían a las escuelas a cargo de la Económica más de 400 alumnas. Además de estas cuatro escuelas, que fueron las de mayores logros y continuidad, la Sociedad Matritense emprendió también otros seis establecimientos de enseñanza, dedicados a otras actividades de la industria popular: escuelas de encajes, de bordados, de blondas, o de flores, todas ellas más efímeras ${ }^{54}$.

El modelo de la Matritense se extendería por otras Sociedades y pronto se crearon escuelas patrióticas por toda la geografía española. Una de las que desempeñó una actividad educativa más activa fue la Sociedad de Sevilla. En 1778, a instancias de su socio Jovellanos, oidor de la Audiencia, creó escuelas de hilados en los barrios de Triana y San Lorenzo ${ }^{55}$, donde las niñas aprendían labores del hilado y rudimentos de lectura, escritura y doctrina cristiana. Concluido el aprendizaje, recibían tornos y lino para establecerse por su cuenta. En estas escuelas, se enseñaba también a hilar a las mujeres sevillanas. Más tarde la Sociedad promovió escuelas en otras localidades: Bonares, Los Palacios, Ayamonte, Sanlúcar, etc. También la Sociedad Aragonesa creó en 1778 una escuela dedicada al hilado del lino, estambre, seda y cáñamo, costeada con sus fondos, que hizo muy poco por la enseñanza de primeras letras de las niñas por falta de preparación de las maestras. Siempre estuvo bajo la supervisión de curadores varones, pues los intentos por crear una comisión de señoras para su supervisión fueron fallidos. Muchos más ejemplos podrían ponerse, pues sabemos que funcionaron en Ávila, León, Lugo, Santiago, Soria, Valladolid, Valencia, Vélez Málaga o Zamora.

54 DEMERSON, P.: "Las escuelas patrióticas de Madrid entre 1787 y 1808”, en Las Reales Sociedades Económicas de Amigos del País y su obra, San Sebastián, 1972, pp. 191-205 y NEGRÍN FAJARDO, O.: La educación popular en la España de la segunda mitad del siglo XVIII. Las actividades educativas de la Sociedad Económica Matritense de Amigos del País, Madrid, 1987, pp. 121-130.

55 CALDERÓN ESPAÑA, C.: La Real Sociedad Económica Sevillana de Amigos del País: su proyección educativa (1775-1900), Sevilla, Universidad, 1993. 
No faltaron tampoco las iniciativas de enseñanza profesional destinada a los niños. En este caso se crearon sobre todo escuelas de dibujo, pues la habilidad del diseño se consideraba de gran utilidad para los artesanos. Alcanzaron especial relieve las de Madrid, Zaragoza, Valencia, Palma de Mallorca, Valladolid, Zamora, Cuenca o León. En Andalucía crearon escuelas de dibujo las sociedades de Jerez, Baeza y Granada. Esta última recibió incluso una dotación sobre los propios de la ciudad y es sin duda una de sus realizaciones más exitosas del instituto granadino.

Aunque la enseñanza primaria fue el nivel al que dedicaron los Amigos del País mayores esfuerzos, en algunas Sociedades se fomentó la enseñanza secundaria, e incluso de algunos contenidos científicos. Las económicas de Vera, Granada y Osuna crearon escuelas de latinidad, la de Granada una Académica de Química y Botánica y las de Osuna y Sevilla tertulias matemáticas. En esta última, su socio el poeta Blanco White, creó un Colegio de Humanidades donde se enseñaba poética, oratoria y francés. En general todas estas iniciativas fueron de poca continuidad y escasamente relevantes.

\section{El desarrollo económico}

El otro gran campo de actuación de los Amigos del País era el fomento de la economía. La agricultura fue objeto de los mayores desvelos. Incluso una sociedad tan preocupada por la industria y el comercio como la Bascongada, dedicó a la agricultura sus mayores esfuerzos y gran parte de sus fondos. En un momento en que las ideas fisiocráticas se extendían por doquier, las comisiones de agricultura promovían los conocimientos agronómicos (lectura de tratados de agronomía y redacción de memorias) y la implantación entre los labradores de mejoras técnicas, casi siempre por medio de premios. Las Sociedades se convirtieron en academias prácticas que difundían los adelantos de los países más avanzados: rotación de cultivos, asociación agricultura-ganadería, extensión de regadíos, plantas industriales, plantíos de árboles, cercados, etc. Algunas regiones, en particular las periféricas, como Valencia, Aragón, la Rioja, Mallorca, Asturias y la Andalucía mediterránea se beneficiaron de mejoras sustanciales en este campo ${ }^{56}$.

La Sociedad Bascongada, por ejemplo, preconizó acciones diferentes para reformar la agricultura de las comarcas atlánticas y de la Llanada de Álava. Siguiendo las premisas de los agrónomos franceses e ingleses, intentó elevar la productividad por medio de la importación de semillas de Inglaterra, Francia y Holanda, mejora de sembrado y abonado, mecanización de labores, rotación de cultivos, extensión de bosques

56 PIQUERAS HABA, J.: Sociedades Económicas y fomento de la agricultura en España, 1765 1850, Valencia, Generalitat Valenciana,1992. 
y plantas industriales (lino y colza, sobre todo), para favorecer la industria local. Al mismo tiempo promocionó el ganado ovino, imprescindible para la producción de estiércol ${ }^{57}$. Sin alcanzar estas cotas de modernidad, todas las Económicas trabajaron por mejorar la agricultura de sus respectivas zonas. Es muy destacable el esfuerzo por promover la expansión de nuevos cultivos alimenticios, que contribuyeran a paliar las carencias de ciertas regiones; así la Económica de Asturias hizo una fuerte campaña a favor del cultivo del maíz y las Sociedades de Motril y Valencia con respecto al arroz. Tampoco hay que olvidar el esfuerzo de esta última por aclimatación del cacahuete. Más importantes, aunque tardaran en fructificar, son los esfuerzos de numerosas Económicas por difundir el cultivo de la patata y sobre todo por su aceptación como alimento humano ${ }^{58}$.

La preocupación por los cultivos más característicos de la región fue una constante en todas las Económicas. La sociedad malagueña, por ejemplo, se ocupó de la vid y del fomento del regadío en sus vegas. Igual preocupación por la vid mostró la Sociedad de la Rioja, que nació como sociedad de cosecheros. Una de sus preocupaciones fue la construcción de un camino que, recorriendo las zonas productoras, diera salida al vino hacia Santander, Bilbao o la frontera con Francia ${ }^{59}$. El cultivo del azúcar fue objeto de especial atención de las Económicas de Vélez Málaga, Motril y Almuñécar y el fomento del olivar y la mejora de la calidad del aceite ocuparon a Sociedades de Aragón, Valencia y Mallorca, así como a las de Baeza y Jaén. La Sociedad de Valencia promovió los cultivos de morales y moreras, base de la cría del gusano de seda, por medio de memorias y premios. Las sederías valencianas vivieron un momento de expansión y prosperidad que se extendió hasta la invasión napoleónica; en el mismo sentido trabajaron también las Sociedades de Granada y Vélez Málaga, para reactivar la producción de seda de la zona, entonces en decadencia. Fue general la preocupación por fomentar el cultivo de fibras textiles, para paliar el déficit de estas materias primas. Es destacable la labor de la Económica de Valencia por la difusión del cultivo del algodón, aunque en fecha tardía. En menor medida también lo difundirían otras andaluzas, como las Económicas de Jaén, Cabra y Lucena, que promovió también los cultivos de lino y cáñamo.

Las experiencias para mejorar las técnicas de cultivo fueron muy abundantes: la Sociedad de Baeza, por ejemplo, realizó rotaciones de cultivos y ofreció parcelas

57 ASTIGARRAGA, J.: Los ilustrados vascos..., op. cit., pp. 152-158.

58 PIQUERAS HABA, J.: Sociedades..., op. cit., capítulos II y IV y CASTELLANO CASTELLANO, J. L.: El Siglo de las Luces. Agricultura y sociedad motrileña, Granada, Ingenio, 2011.

59 MERINO, J. J. Bta.: "Cómo se construyeron las primeras carreteras de la Rioja, labor de la Real Sociedad Económica Riojana”, en Las Reales Sociedades Económicas de Amigos del País y su obra, San Sebastián, CSIC, 1972, pp. 377-387. 
de tierra a los pegujaleros para introducir estas innovaciones; la de la capital jiennense dotó sustanciosos premios para difundir nuevas técnicas del laboreo de la tierra. Las Sociedades de Vera y Granada intentaron fomentar los regadíos, aunque con escaso éxito; la de Almuñécar proyectó la construcción de un embalse en el rio Verde, y la de Jaén diseñó varios canales de riego en el Guadalbullón, que se harían realidad en el siglo XIX.

Pero probablemente la acción más relevante de las Económicas respecto a la agricultura sea la activa participación que tuvo la Matritense en el proceso, fallido, de elaboración de una Ley Agraria. El debate suscitado en el Consejo de Castilla por la llegada de quejas de los labradores y sus representantes sobre los arrendamientos, fue transferido a la Económica Matritense que encargo a su comisión de Agricultura su estudio. Delegado el tema más tarde en su socio Jovellanos, el Informe sobre la ley Agraria, es el producto tardío de este debate en un momento en que el gobierno había abandonado ya la idea de promulgar una ley que regulara las relaciones económicas en el campo ${ }^{60}$.

Las comisiones de manufacturas e industria fueron las más activas, después de las de agricultura. Probablemente fue la Sociedad Bascongada, especialmente en sus primeros años, la que tuvo una mayor preocupación por este sector y llevó a cabo los programas más ambiciosos. Los mayores esfuerzos se centraron en la siderurgia e industria pesquera. La primera se fomentó sobre todo en Guipúzcoa. Además de conseguir la unificación de pesos y medidas del hierro y del carbón, se intentó mejorar las técnicas de explotación, y complementar la producción de hierro en barras, con la de chapa, herramientas y quincallería, para conseguir una mayor rentabilidad. Especial significación tuvo la creación de compañías industriales que proporcionaran capitales a las ferrerías de la zona, manufacturas dispersas dependientes del capital comercial. Las Compañías de acero y de cuchillos de Vergara son dos de las realizaciones más emblemáticas en este campo. La pesca, por su parte, fue promocionada sobre todo en Vizcaya, a través de la creación de la Compañía de pesca de Bilbao, dedicada a la salazón y curado de pescado, para eliminar la dependencia del pescado salado extranjero ${ }^{61}$. La Bascongada no dudo en solicitar exenciones de impuestos aduaneros para asegurar el éxito de estas empresas. En una línea inspirada en la or-

60 ANES, G.: "El Informe sobre la Ley agraria y la Real Sociedad Económica Matritense de Amigos del País", en Economía e Ilustración..., op. cit., pp. 95-138 y del mismo autor: La ley agraria, Madrid, Alianza Editorial, 1995; ORTEGA LÓPEZ, M.: La lucha por la tierra en la Corona de Castilla al final del Antiguo Régimen. El expediente de Ley Agraria, Madrid, Ministerio de Agricultura, 1986, y JOVELLANOS, G. M. de: Informe de la Sociedad Económica de esta Corte al Real y Supremo Consejo de Castilla en el expediente de Ley Agraria..., Madrid, Imprenta de Sancha, 1795.

61 AStigarRAGA, J.: "La Compañía General de Pesca Marítima de las costas del mar Cantábrico" (1770-1782)", BRSVAP, XLVIII (1992), pp. 137-158. 
ganización vasca, la Sociedad Económica de Asturias se preocupó en sus primeros tiempos por la industria minera, aunque la falta de medios económicos impidió iniciativas relevantes, las más importantes se llevarían a cabo a través del Instituto asturiano de Gijón ${ }^{62}$. También intentó fomentar, aunque con poco éxito, la industria de salazón, para dar salida a su abundante producción pesquera.

El resto de las Económicas, más influidas por el modelo de la Matritense, se centraron más en el fomento de las manufacturas textiles, el sector industrial más importante del Antiguo Régimen. Los mayores esfuerzos se destinaron a promover las manufacturas populares o bastas, muy en la línea de Campomanes de crear una industria popular que fuera complemento de la ocupación agrícola del campesinado ${ }^{63}$.

Las Económicas intentaron restablecer las manufacturas existentes en sus distintas regiones y sacarlas de la decadencia en que se encontraban. Así la Sociedad Segoviana intentó revitalizar la producción de paños en esta ciudad, lo mismo que la de Valladolid, mientras la de Valencia se ocupaba en relanzar la producción de tejidos de seda. La Sociedad de Córdoba se preocupó del restablecimiento de sus manufacturas de seda y cuero y la de Baeza de las de lana, muy relevantes en el siglo XVI. Con frecuencia la acción se centró en espolear la iniciativa privada por medio de premios o en la entrega de materia prima y utensilios más modernos que los utilizados (telares, tornos, etc.).

En otras ocasiones, las Sociedades fueron especialmente activas y crearon sus propias fábricas. En estos casos se trató siempre de manufacturas bastas, con mano de obra poco especializada, que proporcionaban empleo a la vez que un producto barato y asequible a las clases populares. Así la Sociedad de Vera, con un préstamo de los propios, creó una fábrica-almacén de esparto y cáñamo que llegó a dar trabajo a más de 100 personas. La Económica de Jaén fundó una casa de labor con escuela de hilados a torno para las niñas y una fábrica de esparto, que ocupaba a pobres, ancianos e impedidos, para evitar su mendicidad. Fue uno de sus logros más importantes. También en Baeza se estableció, en el antiguo colegio de la Compañía de Jesús, una fábrica de hilazas de lana bajo la dirección de la Sociedad. Por su parte la Sociedad de Granada supervisaba la real fábrica de lonas de la ciudad, que daba trabajo a más de 2.000 operarios. Esta misma Sociedad avaló con sus fondos el establecimiento de una fábrica de indianas y lienzos pintados, pero esta iniciativa resultó un fracaso.

62 CASO GONZÁLEZ, J. M.: "El Real Instituto Asturiano de Náutica y Mineralogía”, en CASO GONZÁLEZ, José Miguel (ed.): Asturias y la Ilustración, Oviedo, Principado de Asturias, 1996, pp. 161185 .

63 CAMPOMANES, P. R. de: Discurso sobre el fomento..., op. cit., cap. 9 y LLOMBART, V.: "Un programa patriótico escalonado de fomento económico y promoción del empleo en el reinado de Carlos III". Estudio preliminar a CAMPOMANES, P. R. de: Obras sobre la industria y la educación popular, t. I, Oviedo, Instituto Feijoo, 2009. 
Un aspecto interesante a tener en cuenta es la relación de las Económicas con los gremios de su ciudad. Campomanes, consciente de la rémora que estas corporaciones representaban para la modernización y competitividad, proponía que las Económicas revisaran sus ordenanzas y propusieran al Consejo las modificaciones oportunas. Es bien conocida la estrecha relación de los Amigos del País aragoneses con los gremios de la ciudad de Zaragoza, en su intento de modernizar sus disposiciones, o la tarea que en el mismo sentido se desarrolló desde la Sociedad de Segovia. Los "Socios protectores de los oficios" se encargaban de estas tareas ${ }^{64}$.

Las comisiones de comercio realizaron tareas de carácter más teórico, centrándose en la lectura de escritos y tratados económicos y en la redacción de memorias donde se analizaban los problemas del sector. Por lo general propugnaron en estas memorias medidas liberalizadoras, en sus trabajos se respira un aire favorable a los decretos de libre comercio promulgados en estos años por la administración.

En el marco de los debates sobre tema económico atendidos por los Amigos del País, conviene hacer referencia al papel desempeñado en el fomento de la Economía política, denominación que la ciencia económica recibía entonces. Llombart y Astigarraga han prestado atención a la labor desarrollada en este campo, no dudando en llamarlas, parafraseando a Campomanes, "antorchas de la Economía"65. Las Sociedades actuaron como centros importadores y difusores en España de la literatura económica europea, sobre todo a través de traducciones de autores tan importantes como Bielfeld, Necker, Turgot, Condillac, Justi, Filangieri, Genovesi o Melón. Así mismo destacan que los principales escritos económicos redactados en nuestro país durante esta etapa se materializaron a través de las Económicas y que, en algunos casos, estos escritos tuvieron incidencia en las medidas reformistas del gobierno. Conviene señalar también en este campo la creación de una cátedra de Economía política por la Sociedad de Zaragoza, donde su titular Lorenzo Normante defendía el lujo, la licitud del préstamo a interés, o se quejaba de los perjuicios que el celibato hacía a la riqueza demográfica del país ${ }^{66}$.

También en esta referencia al mundo de las ideas, convendría señalar la significación de las Económicas en el campo político. Aunque diseñadas para respaldar la acción reformista del estado, funcionaron también como un importante cauce de ac-

64 FORNIES CASALS, J. F.: La Real Sociedad Aragonesa de Amigos del País en el periodo de la Ilustración (1776-1808): Sus relaciones con el artesanado y la industria, Madrid, CECA, 1978; ENCISO RECIO, L. M.: Las Sociedades ..., op. cit., p. 160.

65 LLOMBART ROSA, V. y ASTIGARRAGA GOENAGA, J.: "Las primeras "antorchas de la economía": las sociedades económicas de amigos del país en el siglo XVIII”, en FUENTES QUINTANA, E. (dir.): Economía y economistas españoles. 3. La Ilustración, Madrid, Galaxia Gutenberg, 1999, pp. 677707. La difusión de la economía política en pp. 699-702.

66 FORNIÉS CASALS, J.F.: "La Cátedra de Economía civil y comercio de Zaragoza en el periodo de la Ilustración (1784-1808)", Información comercial española, 512 (1976), pp.108-118. 
ción política que contribuyó a ir creando entre sus miembros la conciencia ciudadana que conduciría hacia el liberalismo ${ }^{67}$.

Por último, no debe acabar este repaso a las actividades desempeñadas por las Económicas sin hacer referencia a su labor benéfico-asistencial. En una sociedad donde la existencia de grandes bolsas de pobreza era un rasgo estructural, los Amigos del País desempeñaron una importante labor intentando paliar los efectos de esta lacra social, mostrando una concepción bastante moderna, al intentar socorrer al pobre proporcionándole los medios para ganarse el sustento. El fomento de la enseñanza de los oficios y la creación de manufacturas populares o bastas es, sin duda, el campo de actuación más importante dentro de su acción benéfica. No obstante, en algunos institutos se llevaron a cabo otras iniciativas con una finalidad benéfica en un sentido más estricto. Es destacable, por ejemplo, la labor de la Económica de Asturias, en coordinación con la Junta de Caridad, recogiendo a los pobres en el Real Hospicio y dando ocupación útil a los que podían trabajar ${ }^{68}$. De igual manera, la Sociedad de Osuna fundó un hospicio-escuela para niñas huérfanas, donde aprendían un oficio, e intentó fundar una casa de corrección de mujeres, pero este proyecto no se hizo realidad. Ya se ha destacado el marcado carácter benéfico que tenía la casa de labor fundada por la Económica de Jaén, destinada a niñas pobres y ancianos. Otros ejemplos podrían ponerse.

En momentos desesperados, de una coyuntura económica especialmente negativa, algunas Sociedades intentaron paliar los efectos del hambre entre los más pobres. Así en los años especialmente duros de principios del siglo XIX, procedieron al reparto de "sopas económicas" (adaptación de las sopas alemanas Rumford), elaboradas a base de diferentes verduras y patatas. En los primeros meses de 1804 y 1805 la Económica de Granada, por ejemplo, repartió más de 27.000 raciones, costeadas en su mayor parte con aportaciones de sus socios. La Económica de Asturias de nuevo en combinación con la Junta de Caridad, llevó a cabo un plan de socorros que repartió más de 350.000 raciones. El ejemplo de la Matritense fue también decisivo en este asunto. La Económica de la capital no solo actuó en los citados años citados, sino que volvería a hacerlo durante la terrible crisis alimentaria de $1812^{69}$.

67 FRANCO RUBIO, G.: "Las Sociedades Económicas de Amigos del País: Un observatorio privilegiado para la práctica política y el nacimiento de la ciudadanía a finales del Antiguo Régimen”, en ASTIGARRAGA, J., LÓPEZ-CORDÓN, M.V. y URKÍA, J. M. (eds.): Ilustración, ilustraciones, San Sebastián, Ministerio de Cultura-Sociedad Bascongada, 2009, pp. 351-368.

68 JUNCEDA AVELLO, E.: Historia del Real Hospicio y Hospital Real de la ciudad de Oviedo, Oviedo, Instituto de Estudios Asturianos, 1984 y SORIA MEDINA, E.: La Sociedad... de Osuna, op. cit., pp. 94-102.

69 FAYA DÍAZ, M.Á.: "La Sociedad... de Asturias", art. cit., p. 495; ESPADAS BURGOS, M.: "La Sociedad Económica Matritense y el hambre de 1812", en Las Reales Sociedades Económicas de Amigos del País y su obra, San Sebastián, CSIC, 1972, pp. 207-222. 


\section{Balance de resultados}

Una vez expuesta esta visión panorámica, obligadamente rápida y breve, sobre las realizaciones de las Económicas, cabe hacer un balance de su actividad y preguntarse si cumplieron los objetivos para los cuales habían sido creadas por el gobierno. Fue algo que ya se plantearon sus protagonistas. Aunque el juicio que merecieron fue en general favorable, Sempere y Guarinos, por ejemplo, no duda en considerarlas "Uno de los sucesos más notables del reynado de Carlos III"70 y Jovellanos se refiere a ellas como "la más perfecta de todas las instituciones políticas" y las califica de "feliz revolución"71, ya entre sus contemporáneos se alzaron algunas voces críticas. Francisco Cabarrús, activo socio de la Matritense, se quejaba: "Las Sociedades Patrióticas tienen... varios defectos que impedirán o retardarán las ventajas que el Estado deber prometerse de su formación. Necesitan fondos"72. El desfase entre proyectos y realidad era patente y la falta de medios se hacía evidente frenando las realizaciones.

Bastante parecida es la posición de la historiografía que las ha estudiado. Aunque en general se las muestra como una de las iniciativas más exitosas del reinado de Carlos III, un amplio elenco de autores que van desde los trabajos clásicos de Sarrailh, Carande, Anes, los Demerson, Aguilar Piñal o Enciso, hasta las monografías más recientes, como las de Astigarraga, Llombart, Lluch o Piqueras, entre otros, aunque destacan que las Económicas realizaron aportaciones en los campos de la educación, economía, beneficencia y cultura, suponiendo un importante avance en la modernización y progreso del país, no dudan en mostrar el desfase entre los proyectos y las realizaciones concretas, así como las limitaciones prácticas a las que se enfrentaron.

La multiplicación de estudios y monografías sobre Sociedades concretas, que permite conocer con cierto detalle sus logros, hasta el punto en que se puede considerar hoy este tema de investigación como prácticamente agotado, nos sitúa en condiciones de expresar una valoración más matizada y diversa. Conviene, en consecuencia, distinguir entre las Sociedades más activas, erigidas en ciudades importantes, la mayoría de la periferia del país, con un ámbito de acción regional, con una amplia base

70 SEMPERE Y GUARINOS, J.: Ensayo de una biblioteca española de los mejores escritores del reynado de Carlos III, Madrid, Imprenta Real, 1789, t. V, pp. 135 y 148.

71 JOVEllanOS, G. M. de: Elogio de Carlos III, leído a la Real Sociedad de Madrid por el socio..., Madrid, Imprenta de la viuda de Ibarra, 1789, pp. 44 y 52.

72 CABARRÚS, F.: Elogio del Excmo. Sr. Conde de Gausa, que en la junta general celebrada por la Real Sociedad de Amigos del País de Madrid en 24 de diciembre de 1785 leyó el socio D. ..., Madrid, Imp. de la Viuda de Ibarra, Hijos y Compañía, 1786, nota XXXI, p. 92. 
social y elevado número de socios y unos medios económicos mayores -como las Económicas Matritense, de Sevilla, Granada, Zaragoza, Valencia, Asturias, Santiago, o la propia Bascongada-, capaces de protagonizar iniciativas importantes, tanto en materia económica, como en el campo educativo, que contribuyeron a una cierta modernización y apertura a los avances europeos más destacables, de otras sociedades nacidas en ciudades menos populosas, casi siempre capitales de provincia, con un número de socios menor y unos medios económicos mucho más limitados, como es el caso de los institutos de Jaén, Toledo, Ávila, León, Valladolid, etc., cuyo balance es mucho más modesto. Por último habría también que diferenciar a otras Económicas fundadas en poblaciones pequeñas, sin medios materiales ni humanos suficientes, ya condenadas al fracaso desde su nacimiento.

Pero en todas ellas, incluso en las más importantes, no deja de hacerse patente el desfase entre la amplitud de objetivos con que las concibió el proyecto de Campomanes y proclamaban sus estatutos y las realizaciones concretas que a lo largo de la etapa que nos ocupa fueron capaces de llevar a cabo. De este desfase tuvo mucha responsabilidad la situación económica de estos cuerpos, que no contaron con dotación fija y estuvieron siempre a expensas de las cuotas de sus socios y de otras aportaciones extraordinarias, a todas luces insuficientes. Es lógico que con estos medios económicos tan exiguos la mayoría de las veces muchos proyectos se estrellaran con la falta de fondos. Pero ni siquiera un problema estructural tan serio como la falta de dotación explica por sí mismo el relativo fracaso de estas instituciones. La propia dinámica del programa reformista del Despotismo Ilustrado nos puede explicar mejor la modestia de estas realizaciones. Un programa de reformas, en el campo educativo y económico sobre todo, que tuviera como límite el mantenimiento del orden social estamental, como era el que nos ocupa, nacía lastrado forzosamente. Las Económicas podían modernizar, hacer crecer la economía, o difundir la educación entre las capas populares, pero siempre sin alterar los principios básicos de la sociedad. La diferencia de intereses de los diversos grupos sociales que albergaban estas instituciones condenaba al fracaso muchas de las iniciativas concretas. Por todo ello, el balance que la actividad de las Económicas arroja tiene que ser forzosamente modesto, como lo es de la mayoría de las reformas preconizadas por los ilustrados, que pretendían hacer meros retoques del panorama socioeconómico, adaptados al crecimiento experimentado en la época por la sociedad estamental, sin afectar a las estructuras sociales del Antiguo Régimen. 